\title{
Alkaloid profiling in Galanthus gracilis Celak. from western Turkey by GC/MS
}

\author{
Çiğdem Karakoyun (c) \\ Department of Pharmacognosy, Faculty of Pharmacy, Ege University, Bornova 35100 Izmir, Türkiye
}

Cite this article as: Karakoyun C.. (2018) Alkaloid profiling in Galanthus gracilis Celak. from western Turkey by GC/MS. Istanbul J Pharm 48 (3): 73-75.

\begin{abstract}
Galanthus L. is generally acknowledged as a valuable biological source due to its Amaryllidaceae alkaloids with unusual chemical structures and a wide variety of biological activities. Among these alkaloids, galanthamine is the first example of their practical application in medicine as a potent and selective inhibitor of the enzyme acetylcholinesterase, and already present on the market as a therapeutic agent for Alzheimer's disease. Lycorine is the main Amaryllidaceae alkaloid deeply investigated for its biological activity for many years. In this study the alkaloidal profile of $G$. gracilis collected from western Aegean (Alankıyı/Bayındır) will be illustrated for the first time. GC-MS profiling was carried out on the crude alkaloidal extract obtained from dried and powdered plant material. 11 alkaloids were detected by GC-MS, including graciline, demethylhomolycorine and tazettine as the major ones.
\end{abstract}

Keywords: Galanthus gracilis, Amaryllidaceae, graciline, demethylhomolycorine, tazettine

\section{INTRODUCTION}

Amaryllidaceae is a monocotyledon family which is formed by about 85 genera and 1100 species comprising mostly tropical or subtropical plants. Galanthus L. is a very interesting genus belonging to the family Amaryllidaceae considered as a very large family with 85 genera and 1100 species (Evans et al. 2002). The genus Galanthus L. (Amaryllidaceae) is represented by 14 species (15 taxa) in Turkey (Davis 2006). This genus has been very well known as producers of numerous alkaloids with interesting chemical structures and biological activities such as antitumor, antiviral and acetylcholinesterase inhibitory activity. Previous reports on the alkaloids of this genus reveal that Galanthus species possess Amaryllidaceae alkaloids with potentials to be models for new synthetic therapeutic compounds. The most reputed Amaryllidaceae alkaloid galanthamine is a drug prescribed for Alzheimer's disease and it is widely used all around the world (Gabrielsen et al. 1992; Lopez et al. 2002).

Within the course of some ongoing phytochemical studies on Turkish Galanthus taxa, G. gracilis Celak.has been collected from different localities and afforded number of new and known alkaloids. The most remarkable results of these researches were the presence of a unique subgroup of the Amaryllidaceae alkaloids called gracilines and the isolation of an unusual pentacyclic dinitrogenous alkaloid called gracilamine (Noyan et al. 1998; Unver et al. 1999; UnverKaya 2005; Bozkurt-Sarikaya et al. 2014). Based on previous findings, G. gracilis is a valuable source for alkaloids with interesting chemical structures and a wide range of bioactivities. In the present study, we aimed to investigate the alkaloidal composition of G. gracilis collected from a different localisation considering the possible differences depending on climatic and geographical factors. The results have been compared with the ones of previous findings.

This study was presented at the "63. International Congress and Annual Meeting of the Society of Medicinal Plants and Natural Product Research-GA 2015 ”, “23-27 August 2015”, “Budapest, Hungary”. 


\section{MATERIAL AND METHODS}

\section{Plant material}

G. gracilis was collected from Alankıyı/Bayındır in the province of İmir and identified by Prof. Dr. Mustafa Ali Onur from Ege University, Faculty of Pharmacy, Department of Pharmacognosy.

\section{Extraction}

The extract was prepared from the bulbs of G. gracilis. Briefly, air-dried and powdered plant material $(500 \mathrm{mg}$ ) was extracted three times using methanol $(5 \mathrm{~mL})$ in an ultrasonic bath for 30 minutes at room temperature. After the extraction procedure, solvent was evaporated under vacuo. The residue was dissolved in $10 \mathrm{~mL} 2 \% \mathrm{H}_{2} \mathrm{SO}_{4^{\prime}}$ and the neutral compounds were removed with petroleum ether $(3 \times 10 \mathrm{~mL})$. The acidic aqueous phases were basified with $25 \% \mathrm{NH}_{4} \mathrm{OH}$ up to $\mathrm{pH}$ 9-10 and extracted with $\mathrm{CHCl}_{3}(3 \times 10 \mathrm{~mL})$. The combined chloroform extracts were then dried over anhydrous $\mathrm{Na}_{2} \mathrm{SO}_{4}$ and filtered through filter paper, and the organic solvent was distilled under vacuo to obtain the alkaloidal extract. The extract was dissolved in methanol (1 mg extract in $500 \mu \mathrm{L} \mathrm{CH} \mathrm{CH}_{3} \mathrm{OH}$ ) prior to GC/MS Analysis.

\section{GC-MS analysis}

Thermo GC-Trace Ultra Ver: 2.0., Thermo MS DSQ II (Thermo Fisher Scientific, San Jose, CA, USA) was used to carry out GCMS analysis in the electron impact mode (El, $70 \mathrm{eV}$ ).

The oven temperature was programmed as: $80^{\circ} \mathrm{C}$ for $1 \mathrm{~min}$, $80-250^{\circ} \mathrm{C}\left(10{ }^{\circ} \mathrm{C} \mathrm{X} \mathrm{m^{-1 }}{ }^{-1}\right), 250^{\circ} \mathrm{C}$ for $2 \mathrm{~min}, 250-300^{\circ} \mathrm{C}\left(10{ }^{\circ} \mathrm{C}\right.$

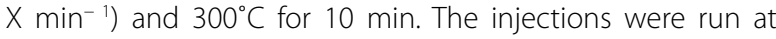
$250^{\circ} \mathrm{C}$, in the splitless mode. A TR-5 MS column (30 m $\times 0.25$ $\mathrm{mm} \times 0.25 \mu \mathrm{m}$ ) and helium (at a flow rate of $0.8 \mathrm{~mL} \mathrm{~min}{ }^{-1}$ ) were used as a stationary phase and carrier gas respectively.1 mg extract was dissolved in $500 \mu \mathrm{L}$ methanol. Mass spectra of chromatographic peaks were analysed and evaluated using software Xcalibur (version 2.07; Thermo Fisher Scientific San Jose, CA, USA). Identification of the compounds were followed out checking the mass spectral fragmentations against the standard reference spectra from NIST MS Search 2.0 (National Institute of Standards and Technology, Gaithersburg, MD, USA) or the spectra of the authentic standards (S) which were previously isolated by our working team or spectral data procured from the literature. The percentage of the total ion current (TIC) for all the compounds were calculated and given as can be seen in Table 1. The area under the GC-MS peaks points out not only the concentration but also the intensity of mass spectral fragmentation of detected compounds. The ratio of each compound in the extract was exhibited as the percentage of the total alkaloid content in Table 1 and Figure 1.

The area of the GC-MS peaks depends not only on the concentration of the related compounds but also on the intensity of their mass spectral fragmentation.

\section{RESULTS AND DISCUSSION}

As previous reports shows, Galanthus gracilis collected from Yılanlıdağ/Muğla is hosting plant for 20 alkaloids of 7 Amaryllidaceae skeleton types which are phenanthridine, homolycorine, galanthamine, crinine, indole, tazettine and lycorine types. Also these previous findings show that; homolycorine and 8-O-demethylhomolycorine are the main alkaloids for the aerial parts and bulbs of the plant respectively (BozkurtSarıkaya et al. 2014).

Table 1. Chemical composition of the G. gracilis bulb methanolic extracts on GC/MS analysis Icollected from Alankıyı/Bayındır).

\begin{tabular}{|c|c|c|c|c|}
\hline $\begin{array}{l}\text { Compound } \\
\text { Name }\end{array}$ & $\begin{array}{l}\text { Retention } \\
\text { Time (min) }\end{array}$ & {$[M+]$} & $\mathrm{m} / \mathrm{z}$ (rel.\%) & Bulbs $(\%)$ \\
\hline Graciline type alkaloid-1 & 13.29 & - & 225 (100), 167 (10), 139 (31), 84 (7) & 0.63 \\
\hline Graciline (Sarıkaya et al. 2013) & 15.26 & $283(10)$ & $\begin{array}{l}282(7), 264(4), 254(10), 240(8), 227 \text { (6),226 (21), } \\
225 \text { (100), } 139 \text { (7) }\end{array}$ & 73.2 \\
\hline Graciline type alkaloid-2 & 15.85 & - & $\begin{array}{l}283 \text { (84), } 268 \text { (25), } 254 \text { (43), } 240 \text { (78), } 225 \text { (100), } \\
215 \text { (35), } 197 \text { (29), } 139 \text { (45) }\end{array}$ & 1.63 \\
\hline Graciline type alkaloid-3 & 16.32 & - & $\begin{array}{l}283(100), 254 \text { (26), } 242 \text { (38), } 240 \text { (23), } 228 \text { (68), } \\
225 \text { (23), } 139 \text { (23) }\end{array}$ & 0.49 \\
\hline $\begin{array}{l}\text { Galanthindole } \\
\text { (Bozkurt-Sarikaya et al. 2014) }\end{array}$ & 16.68 & $281(100)$ & $\begin{array}{l}264 \text { (15), } 263 \text { (20), } 262 \text { (22), } 252 \text { (16), } 204 \text { (10), } \\
191 \text { (17), } 132 \text { (15), } 107 \text { (12) }\end{array}$ & 4.98 \\
\hline $\begin{array}{l}\text { 6-0-Methylpretazettine } \\
\text { (Bozkurt-Sarikaya et al. 2014) }\end{array}$ & 17.31 & $345(14)$ & 330 (16), 261 (100), 239 (29), 230 (15), 201 (21) & 0.9 \\
\hline $\begin{array}{l}\text { 6-0-Methylpretazettine isomer } \\
\text { (Bozkurt-Sarikaya et al. 2014) }\end{array}$ & 17.46 & $345(10)$ & 330 (12), 261 (100), 239 (24), 230 (19), 201 (25) & $<0.01$ \\
\hline Tazettine (Berkov et al. 2009) & 17.77 & $331(14)$ & $\begin{array}{l}316 \text { (10), } 298 \text { (17), } 247 \text { (100), } 227 \text { (13), } 211 \text { (13), } \\
201 \text { (19), } 181 \text { (19), } 152 \text { (13), } 115 \text { (17) }\end{array}$ & 5.76 \\
\hline Hippamine (Berkov et al. 2008) & 18.33 & $301(80)$ & 300 (9), 227 (90), 226 (100), 227 (15) & 2.41 \\
\hline $\begin{array}{l}\text { Homolycorine } \\
\text { (Bozkurt-Sarikaya et al. 2014) }\end{array}$ & 18.60 & $315(-)$ & 109 (100), 108 (22), 94 (3) & 2.76 \\
\hline $\begin{array}{l}\text { Demethylhomolycorine } \\
\text { (Bozkurt-Sarikaya et al. 2014) }\end{array}$ & 19.24 & $301(-)$ & 109 (100), 108 (2), 94(2) & 7.24 \\
\hline
\end{tabular}




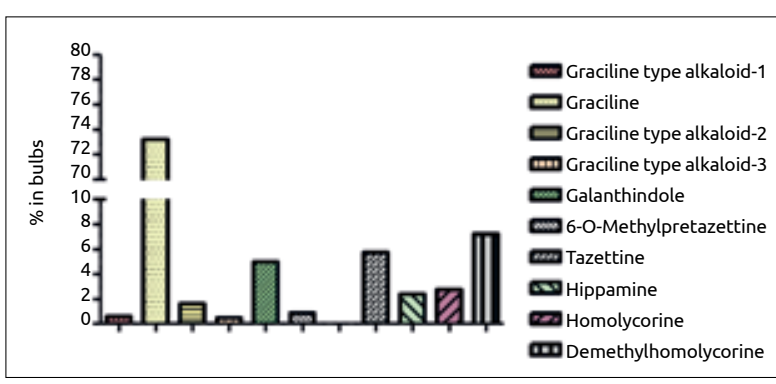

Figure 1. Graphical presentation of total amount percent of each of alkaloids in bulbs for Galanthus gracilis

GC/MS analysis on the bulbs methanolic extract of G. gracilis collected from Alankıyı/Izmir revealed that, this plant is a good source of bioactive compounds with a total of 11 alkaloids as shown in Table 1. The detected alkaloids possessed different skeleton types such as; graciline, indole, tazettine, lycorine and homolycorine. Generally, graciline, homolycorine and tazettine type alkaloids are major alkaloids in the tested material (Table 1). The extract of the bulbs of $G$. gracilis contain graciline as the main alkaloid (73.2\%). Similarly, this extract comprises demethylhomolycorine (7.24\%) and tazettine $(5.76 \%)$ in considerable percentage. In addition an indole type alkaloid, galanthindole, is also found in significant rate (4.98\%).

Aside from Galanthus gracilis; G. elwesii Hook., G. xvalentinei, G. woronowi Losinsk., G. rizehensis and G. reginae-olgae subsp. vernalis were already investigated by GC-MS (Berkov et al. 2004; Bozkurt et al. 2017; Conforti et al. 2010; Sarıkaya et al. 2013; Sarikaya et al. 2013). In terms of alkaloidal content, only Galanthus gracilis and G. xvalentinei nothosubsp. subplicatus are similar by the fact that they contain graciline type alkaloids. Among these interesting two species, Galanthus gracilis seems to have higher relative percentage of graciline types than G. xvalentinei nothosubsp. subplicatus.

\section{CONCLUSION}

It can be concluded that this plant is a valuable source of alkaloids with diverse chemical structures including graciline type alkaloids. The alkaloidal profile of G. gracilis naturally growing in Alankıyı/Bayındır differs from the other samples collected from Kemalpasa/Izmir and Yilanlidag/Mugla (Bozkurt-Sarıkaya et al. 2014; Sarıkaya et al. 2013). G. gracilis has a great value because of its extraordinary alkaloidal profile. Even this plant has completely different compounds such as graciline type alkaloids. The bioactivity of the graciline-type alkaloids is not well studied. Therefore the detection of gracilines in G. gracilis may also encourage chemists to synthesize these alkaloids for the purpose of investigating various bioactivities to be used in drug development studies.

Peer-review: Externally peer-reviewed.

Conflict of Interest: The author has no conflict of interest to declare.

Financial Disclosure: The author declared that this study has received no financial support.

\section{REFERENCES}

- Berkov S, Bastida J, Nikolova M, Viladomat F, Codina C (2008). Rapid TLC/GC-MS identification of acetylcholinesterase inhibitors in alkaloid extracts. Phytochemical Analysis doi: 10.1002/pca.1066. [CrossRef]

- $\quad$ Berkov S, Bastida J, Tsvetkova R, Viladomat F, Codina C (2009). Alkaloids from Sternbergia colchiciflora. Zeitschrift für Naturforschung Section C- A Journal of Biosciences 64: 311-316.

- $\quad$ Berkov S, Sidjimova B, Evstatieva L, Popov S (2004). Intraspecific variability in the alkaloid metabolism of Galanthus elwesii. Phytochemistry 65: 579-586. [CrossRef]

- Bozkurt-Sarıkaya B, Kaya GI, Onur MA, Bastida J, Berkov S, Unver-Somer N (2014). GC/MS Analysis of Amaryllidaceae Alkaloids in Galanthus gracilis. Chemistry of Natural Compounds 50: 573-575. [CrossRef]

- Bozkurt B, Emir A, Kaya Gl, Onur MA, Berkov S, Bastida J, Unver Somer N (2017). Alkaloid profiling of Galanthus woronowii Losinsk. by GC-MS and evaluation of its biological activity. Marmara Pharmaceutical Journal doi: 10.12991/mpj.2017.12. [CrossRef]

- Conforti F, Loizzo MR, Marrelli M, Menichini F, Statti GA, Uzunov D, Menichini F (2010). Quantitative determination of Amaryllidaceae alkaloids from Galanthus reginae-olgae sub$\mathrm{sp}$ vernalis and in vitro activities relevant for neurodegenerative diseases. Pharmaceutical Biology 48: 2-9. [CrossRef]

- Davis AP (2006). Snowdrops, A Monograph of Cultivated Galanthus. In: The Genus Galanthus - Snowdrops in the wild., Griffin Press Publishing Ltd.

- $\quad$ Evans WC, Evans D, Trease GE (2002). Trease and Evans Pharmacognosy. fifteenth ed, Edinburgh, New York, W B Saunders.

- Gabrielsen B, Monath TP, Huggins JW, Kefauver DF, Pettit GR, Groszek G, Hollingshead M, Kirsi JJ, Shannon WM, Schubert EM, Dare J, Ugarkar B, Ussery MA, Phelan MJ (1992). Antiviral (Rna) Activity of Selected Amaryllidaceae Isoquinoline Constituents and Synthesis of Related Substances. Journal of Natural Products doi: Doi 10.1021/ Np50089a003. [CrossRef]

- $\quad$ Lopez S, Bastida J, Viladomat F, Codina C (2002). Acetylcholinesterase inhibitory activity of some Amaryllidaceae alkaloids and Narcissus extracts. Life Sciences doi: 10.1016/ S0024-3205(02)02034-9. [CrossRef]

- $\quad$ Noyan S, Rentsch GH, Onur MA, Gozler T (1998). The gracilines: A novel subgroup of the Amaryllidaceae alkaloids. Heterocycles 48: 1777-1791. [CrossRef]

- Sarıaya BB, Berkov S, Bastida J, Kaya Gl, Unver-Somer N (2013). GC-MS Investigation of Amaryllidaceae alkaloids in Galanthus xvalentine nothosubsp. subplicatus. Natural Product Communications 8: 327-328.

- Sarıkaya BB, Somer NU, Kaya Gl, Onur MA, Bastida J, Berkov S (2013). GC-MS Investigation and Acetylcholinesterase Inhibitory Activity of Galanthus rizehensis. Zeitschrift für Naturforschung Section C-A Journal of Biosciences 68: 118-124. [CrossRef] - $\quad$ Unver N, Kaya Gl (2005). An unusual pentacyclic dinitrogenous alkaloid from Galanthus gracilis. Turkish Journal of Chemistry 29: 547-553.

- Unver N, Noyan S, Gozler T, Onur MA, Gozler B, Hesse M (1999). Three new tazettine-type alkaloids from Galanthus gracilis and Galanthus plicatus subsp. byzantinus. Planta Medica 65: 347-350. [CrossRef] 